\title{
Thiazolidione derivatives targeting the histidine kinase YycG are effective against both planktonic and biofilm-associated Staphylococcus epidermidis
}

\author{
Ren-zheng HUANG ${ }^{1,3, \#, ~ L i-k a n g ~ Z H E N G}{ }^{2, \#}$, Hua-yong LIU ${ }^{1, \#}$, Bin PAN², Jian HU⿱1${ }^{1}$, Tao ZHU ${ }^{1}$, Wei WANG ${ }^{1}$, Dan-bin JIANG ${ }^{3}$, \\ Yang $\mathrm{WU}^{1}$, You-cong $\mathrm{WU}^{1}$, Shi-qing $\mathrm{HAN}^{2, *}$, Di QU ${ }^{1, *}$ \\ ${ }^{1}$ Key Laboratory of Medical Molecular Virology of Ministries of Education and Health, Institute of Medical Microbiology and Institutes \\ of Biomedical Sciences, Shanghai Medical College of Fudan University, Shanghai 200032, China; ${ }^{2}$ College of Biotechnology and Phar- \\ maceutical Engineering, Nanjing University of Technology, Nanjing 210009, China; ${ }^{3}$ Yancheng Third People's Hospital, the Affiliated \\ Yancheng Hospital of Southeast University Medical College, Yancheng 224001, China
}

Aim: To evaluate the efficacies of six derivatives of Compound 2, a novel YycG histidine kinase inhibitor with the thiazolidione core structure in the treatment of medical device-related biofilm infections.

Methods: The minimal inhibitory concentration (MIC) of the derivatives was determined using the macrodilution broth method, and the minimal bactericidal concentration (MBC) was obtained via sub-culturing $100 \mu \mathrm{L}$ from each negative tube from the MIC assay onto drug-free Mueller-Hinton agar plates. Biofilm-killing effect for immature ( 6 h-old) biofilms was examined using a semiquantitative plate assay, and the effect on mature (24 h-old) biofilms was observed under a confocal laser scanning microscope (CLSM).

Results: The derivatives potently suppressed the growth of Staphylococcus epidermidis. The MIC values of the derivatives $\mathrm{H} 2-10$, $\mathrm{H} 2-12, \mathrm{H} 2-20, \mathrm{H} 2-29, \mathrm{H} 2-27$, and H2-28 on S epidermidis ATCC 35984 were $24.3,6.5,6.2,3.3$, 3.1, and 1.5 $\mu \mathrm{g} / \mathrm{mL}$, respectively. The MBC values of these derivatives were 48.6, 52.2, 12.4, 52.6, 12.4, and $6.2 \mu \mathrm{g} / \mathrm{mL}$, respectively. The derivatives killed all bacteria in immature ( 6 h-old) biofilms and eliminated the biofilm proliferation. The derivatives also displayed strong bactericidal activities toward cells in mature (24 h-old) biofilms, whereas they showed low cytotoxicity and hemolytic activity toward Vero cells and human erythrocytes.

Conclusion: The bactericidal and biofilm-killing activities of the new anti-YycG compounds were significantly better than the parent Compound 2.

Keywords: Staphylococcus epidermidis; antibacterial agent; half maximal inhibitory concentration; minimal inhibitory concentration; biofilm-killing activity

Acta Pharmacologica Sinica (2012) 33: 418-425; doi: 10.1038/aps.2011.166; published online 9 Jan 2012

\section{Introduction}

Coagulase-negative Staphylococcus epidermidis (S epidermidis) is one of the most common opportunistic pathogens involved in implanted medical device-associated nosocomial infections ${ }^{[1-3]}$. With the increasing use of implanted medical devices, such as intravascular catheters, artificial pacemakers, cerebrospinal fluid shunts, and artificial organs, $S$ epidermidis biofilm-associated infections have become a common problem. The ability to form biofilms on the surfaces of the implanted devices is the

\footnotetext{
"These authors contributed equally to this work.

* To whom correspondence should be addressed.

E-mail dqu@fudan.edu.cn (Di QU);

hanshiqing@njut.edu.cn (Shi-qing HAN)

Received 2011-05-07 Accepted 2011-10-27
}

primary pathogenic trait of $S$ epidermidis, and the bacteria in the biofilms are resistant to antimicrobial treatments and host immune defenses ${ }^{[4-6]}$. Because of the increasing emergence of multidrug-resistant strains, the discovery of novel antibiotics to combat staphylococcal biofilm infections is imperative ${ }^{[7]}$. Completion of the genome sequencing of $S$ epidermidis ${ }^{[8,9]}$ makes it possible to discover potential antimicrobial agents using genomics-based drug discovery strategies.

The majority of bacteria use a phosphotransfer mechanism termed a two-component system (TCS), comprised of a histidine kinase $(\mathrm{HK})$ and a response regulator (RR), to sense environmental conditions and bring about appropriate changes in cellular behavior ${ }^{[10-12]}$. TCSs are important in regulating the virulence and propagation of pathogenic bacteria ${ }^{[13-15]}$, and they are considered attractive targets for the development of 
novel anti-bacterial drugs. The two-component $\mathrm{YycG} / \mathrm{YycF}$ system, originally identified in Bacillus subtilis ${ }^{[16,17]}$, is highly conserved and specific to low $\mathrm{G}+\mathrm{C}$ gram-positive bacteria, including $S$ epidermidis. YycG/YycF is essential for cell viability, cell wall metabolism, autolysin synthesis, and biofilm formation in staphylococcal species. Upon sensing a signal from the external milieu, YycG autophosphorylates by transferring a phosphate group from ATP to a histidine residue within the kinase and then transferring it to an aspartate residue within the conserved receiver domain of the response regulator YycF. Phosphorylation of $\mathrm{YycF}$ results in changes in its ability to bind gene promoters and regulate transcription ${ }^{[18-20]}$.

Several inhibitors that target YycG in B subtilis, Staphylococcus aureus (S aureus), and $S$ epidermidis have been documented to inhibit bacterial growth ${ }^{[21-23]}$. We previously described two inhibitors (Compounds 2 and 5 ) that target the HK domain of $S$ epidermidis YycG and have bactericidal and biofilm-killing activities $^{[24]}$. To obtain more effective and less toxic inhibitors, the structure of Compound 2 was optimized, and a series of derivatives were designed and synthesized, some of which inhibit the growth of planktonic $S$ epidermidis cells ${ }^{[25]}$. In the present study, we explored the characteristics of these derivatives, including their YycG phosphorylation-inhibiting activity, bactericidal activity, biofilm-killing activity, and cytotoxicity. The inhibitory and bactericidal activities of these derivatives against $S$ aureus were also assessed.

Our study of structure-based modification of a leading antiTCS compound may contribute to the discovery of new antibiotics to treat staphylococcal biofilm infections.

\section{Materials and methods}

Bacterial strains, media, and derivatives of Compound 2

The bacterial strains used in this study were $S$ epidermidis
ATCC 12228 (biofilm negative), S epidermidis ATCC 35984 (biofilm positive), S aureus ATCC 49230, $S$ aureus ATCC 25923, and E coli ATCC 25922. E coli strains were grown in Luria-Bertani (LB) broth, and staphylococcal strains were cultivated in tryptic soy broth medium (TSB; Oxoid Ltd, Basingstoke, UK). The six derivatives of Compound 2 mentioned in this report (including five reported previously ${ }^{[26]}$ and one newly synthesized) are $\mathrm{H} 2-10, \mathrm{H} 2-12, \mathrm{H} 2-20, \mathrm{H} 2-27, \mathrm{H} 2-28$, and $\mathrm{H} 2-29$. These compounds were synthesized by modifying the functional groups while keeping the thiazolidione core structure intact. The structural formulas of the derivatives are listed in Figure 1. To generate the derivative compounds, the terminal (2-methoxy-4-vinyl-phenoxy)-acetic acid functional group of Compound 2 was replaced by a (5-vinyl-furan-2-yl)-benzoic acid fragment with similar structure and by a shortened side alkyl chain, according to the principle of multi-target-directed ligands. The derivatives were dissolved in dimethyl sulfoxide (DMSO; AMRESCO, USA) to create $200 \mathrm{mmol} / \mathrm{L}$ stock solutions.

\section{Expression and purification of the YycG HATPase_c and HisKA domains}

The HisKA and HATPase_c domains (amino acids 370-610, NCBI accession number YP_190074) of YycG (termed YycG') from $S$ epidermidis ATCC 35984 were expressed as a fusion protein with an N-terminal maltose binding protein sixhistidine (MBP-His) tag. The 720-bp YycG ORF was PCRamplified from $S$ epidermidis ATCC 35984 chromosomal DNA with the primers YycG For-BamH I (5'-CGCGGATCCGAACAACAACAAGTCGAACGT-3') and YycG Rev-Xho I (5'-CCGCTCGAGTTATTCATCCCAATCACCGTCT-3'). After digestion with $\mathrm{BamH} \mathrm{I}$ and Xho I, the PCR product was cloned into pET28a (Novagen). The resultant plasmid was trans-

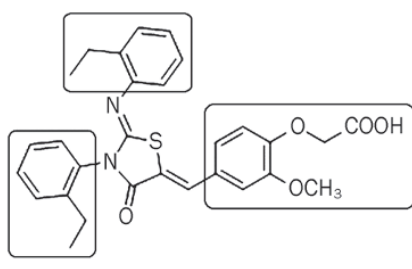

Compound 2

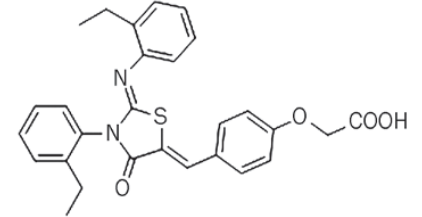

$\mathrm{H} 2-10$

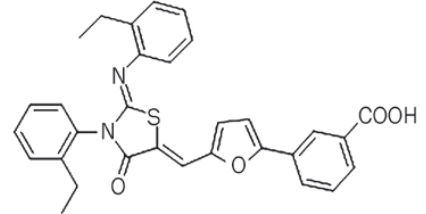

$\mathrm{H} 2-12$

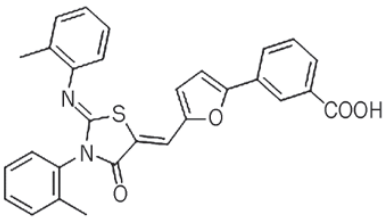

$\mathrm{H} 2-20$
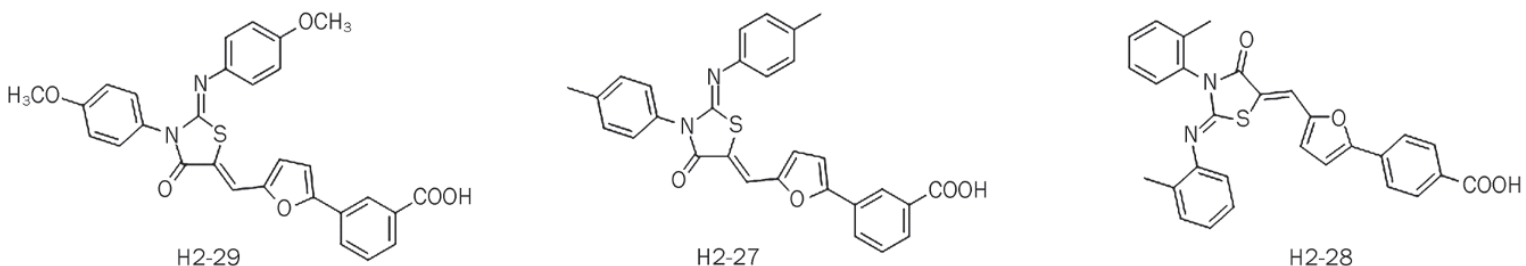

Figure 1. The structures of the thiazolidione derivatives. Based on the thiazolidione core structure of Compound 2 \{2-\{4-\{3-(2-ethylphenyl)-2-[(2ethylphenyl)imino]-4-oxothiazolidin-5-ylidene\}methyl\}-2-methoxyphenoxy\}acetic acid, six derivatives were designed and synthesized by modifying the functional groups through cyclization, aldol condensation, substitution, and hydrolyzation reactions. H2-10, 2-\{4-\{[3-(2-ethylphenyl)-2-[(2-ethylphenyl) imino]-4-oxothiazolidin-5-ylidene\}methyl\}phenoxy\}acetic acid; H2-12, 3-\{5-\{\{3-(2-ethylphenyl)-2-[(2-ethylphenyl)imino]-4-oxothiazolidin-5-ylidene)methyl\} furan-2-yl\}benzoic acid; H2-20, 3-\{5-\{\{4-oxo-3-(o-tolyl)-2-(o-tolylimino)thiazolidin-5-ylidene]methyl\}furan-2-yl\}benzoic acid; H2-27, 3-\{5-\{[4-oxo-3-(p-tolyl)2-(p-tolylimino)thiazolidin-5-ylidene]methyl\}furan-2-yl\}benzoic acid; H2-29, 3-\{5-\{\{3-(4-methoxyphenyl)-2-[(4-methoxyphenyl)imino]-4-oxothiazolidin-5ylidene\}methyl\}furan-2-yl\}benzoic acid; and H2-28, 4-\{5-\{[4-oxo-3-(o-tolyl)-2-(o-tolylimino)thiazolidin-5-ylidene]methyl\}furan-2-yl\}benzoic acid. 
formed into E coli BL21 (DE3). The BL21 (DE3) strain carrying the plasmid was grown in LB to an optical density of 0.6 at 600 $\mathrm{nm}\left(O D_{600}\right)$, and then induced with $0.8 \mathrm{mmol} / \mathrm{L}$ isopropyl $\beta-D$ 1-thiogalactopyranoside (IPTG). After $8 \mathrm{~h}$ induction at $25^{\circ} \mathrm{C}$, the cells were harvested, and recombinant $\mathrm{YycG}^{\prime}$ protein was purified by $\mathrm{Ni}^{2+}$ affinity chromatography using a Ni-NTA column (Qiagen, Germany). The MBP-His-tagged YycG' was then cleaved with TEV protease, and the resultant un-tagged YycG' was further purified by Ni-NTA and Superdex 75 gel filtration columns (GE Healthcare, USA).

\section{Inhibition assay for YycG' autophosphorylation activity}

The Compound 2 derivatives were tested for inhibition of $\mathrm{YycG}^{\prime}$ autophosphorylation using the Kinase-Glo ${ }^{\mathrm{TM}}$ Luminescent Kinase Assay (Promega, Madison, WI, USA) in a solid black flat-bottomed 96-well plate ${ }^{[24]}$. Briefly, $0.13 \mu \mathrm{mol} / \mathrm{L}$ recombinant $Y_{y c G}$ ' was pre-incubated with serial dilutions of the derivatives in reaction buffer $(40 \mathrm{mmol} / \mathrm{L}$ Tris $\mathrm{pH}$ 8.0, $20 \mathrm{mmol} / \mathrm{L} \mathrm{MgCl}_{2}$, and $0.1 \mathrm{mg} / \mathrm{mL} \mathrm{BSA}$ ) at $25^{\circ} \mathrm{C}$ for 30 min. Then, $4 \mu \mathrm{mol} / \mathrm{L}$ ATP was added and the plates were incubated for $30 \mathrm{~min}$ at $25^{\circ} \mathrm{C}$, and Kinase-Glo ${ }^{\mathrm{TM}}$ Reagent was added to detect the remaining ATP, recorded by luminescence measurement (RLU). Recombinant $\mathrm{YycG}_{\mathrm{c}}$ incubated with Compound 2 was used as a positive control, and recombinant protein with no derivative added was used as a negative control in these experiments. The rate of protein phosphorylation (Rp) inhibition by the derivatives was calculated using the equation (Eq 1).

The half maximal inhibitory concentration $\left(\mathrm{IC}_{50}\right.$, the concentration of the derivatives required to inhibit half of the autophosphorylation of the recombinant $\mathrm{YycG}^{\prime}$ ) was determined by Origin 8.0 software (OriginLab, Northampton, USA) ${ }^{[24]}$.

\section{Minimal inhibitory concentration (MIC) and minimal bactericidal concentration (MBC) assays}

MIC assays for the antibacterial activities of the derivatives were performed according to the macrodilution (tube) broth method of the Clinical and Laboratory Standards Institute (CLSI) of America. Briefly, the derivatives were serially diluted twofold into eight tubes containing $4 \mathrm{~mL}$ MuellerHinton Broth (OXOID, UK), yielding final concentrations of $100 \mu \mathrm{g} / \mathrm{mL}$ to $0.78 \mu \mathrm{g} / \mathrm{mL}$. The turbidity of cultures incubated for $6 \mathrm{~h}$ was adjusted to match that of a $0.5 \mathrm{McF}$ arland standard (approximately $10^{8} \mathrm{CFU} / \mathrm{mL}$ ), and $0.02 \mathrm{~mL}$ of the bacterial inoculum was added to each tube. Inoculated broth containing no antibiotic was included as a bacterial growth control and a tube of un-inoculated broth was used as a sterility control. The bacteria were incubated at $37^{\circ} \mathrm{C}$ for $12 \mathrm{~h}$. The lowest concentration that completely inhibits visible growth of the organism as detected by the unaided eye was recorded as the $\mathrm{MIC}^{[27]}$

The MBC was obtained by sub-culturing $100 \mu \mathrm{L}$ from each negative (no visible bacterial growth) tube from the MIC assay onto drug-free Mueller-Hinton agar plates. The plates were incubated at $37^{\circ} \mathrm{C}$ for $24 \mathrm{~h}$, and the MBC was defined as the lowest concentration of drug which produced subcultures growing no more than five colonies on each plate ${ }^{[27]}$.

\section{Biofilm-killing assays}

Biofilm formation was detected using a semiquantitative plate assay $^{[26]}$. An overnight culture of S epidermidis ATCC 35984 was diluted 1:200 into TSB medium, and incubated statically for $6 \mathrm{~h}$ in a polystyrene 96-well plate at $37^{\circ} \mathrm{C}$. Subsequent to the removal of planktonic cells, fresh TSB containing the serially diluted derivatives was added to each biofilm, and the plates were incubated for another $18 \mathrm{~h}$ at $37^{\circ} \mathrm{C}$. After incubation, the wells were washed gently three times with phosphate buffered saline (PBS), fixed with methanol, and stained with $2 \%(w / v)$ crystal violet ${ }^{[28]}$. The absorbance of the wells was determined at $570 \mathrm{~nm}$ using a spectrophotometer (DTX880, Beckman Coulter, USA).

To determine the effect of the derivatives on cell viability in mature biofilms, the Live-Dead Bacterial Viability method (Live-Dead BacLight, Molecular Probes, USA) was used. Overnight cultures of $S$ epidermidis ATCC 35984 grown in TSB medium were subcultured for another $6 \mathrm{~h}$. The turbidity of the culture was adjusted to match that of a $0.5 \mathrm{McF}$ arland standard (approximately $10^{8} \mathrm{CFU} / \mathrm{mL}$ ) and inoculated (1:200) into cover-glass cell-culture dishes (WPI, USA), which were then incubated at $37^{\circ} \mathrm{C}$ for $24 \mathrm{~h}$. After removal of the planktonic cells, fresh TSB containing the derivatives at concentrations corresponding to $4 \times \mathrm{MIC}$ was added, and the dishes were incubated at $37^{\circ} \mathrm{C}$ for another $16 \mathrm{~h}$. After incubation, the dishes were carefully washed three times with normal saline (NS), stained with Live-Dead reagents (containing SYTO 9 and PI) at room temperature for $15 \mathrm{~min}$, and observed under a Leica TCS SP5 confocal laser scanning microscope (CLSM).

\section{Cytotoxicity and erythrocyte hemolysis}

The cytotoxicity of the derivatives to Vero cells (African green monkey kidney cells) was detected using the Cell Proliferation Kit I (Roche, Indianapolis, USA) in 96-well cell culture plates. After exposure of the cells $\left(\sim 10^{4}\right.$ cells per well) to the serially diluted derivatives for $48 \mathrm{~h}$, relative cell numbers were assayed by co-incubation with 3-(4,5-dimethylthiazol2-yl)-2,5-diphenyltetrazolium bromide (MTT) for $4 \mathrm{~h}$ at $37^{\circ} \mathrm{C}$ in $5 \% \mathrm{CO}_{2}$. After incubation, the purple formazan salts were dissolved with DMSO, and the absorbance of each well was measured at 595 and $655 \mathrm{~nm}$ then converted to percentages of the control (cells treated with the solvent, 0.1\% DMSO). The concentration of the derivatives with $50 \%$ cytotoxicity for Vero cells $\left(\mathrm{CC}_{50}\right)$ was calculated using the Origin 8.0 software (Origin Lab, Northampton, USA).

To determine the hemolytic activities of the derivatives on erythrocytes, $5 \%(v / v)$ healthy human erythrocytes re-suspended in NS were co-incubated with the derivatives at MIC,

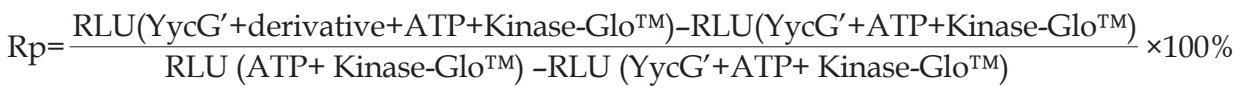


$4 \times \mathrm{MIC}$, or $100 \mu \mathrm{g} / \mathrm{mL}$ for $1 \mathrm{~h}$ at $37^{\circ} \mathrm{C}$ in 96 -well microtiter plates. After the incubation, the suspensions were centrifuged at $350 \times \mathrm{g}$ for $10 \mathrm{~min}$, and the level of hemolysis was determined by measuring the absorbance of the supernatant at 570 $\mathrm{nm}^{[25]}$. Cells treated with DMSO (0.1\%) and Triton-X100 (1\%) were used as negative and positive controls, respectively.

\section{Results}

In our previous study, five derivatives were designed and synthesized based on the chemical structure of Compound $2^{[24,25]}$. The biological characteristics of the Compound $\mathbf{2}$ derivatives, including these five derivatives that were previously reported (H2-10, H2-12, H2-20, H2-29, and H2-27) and the newly synthesized H2-28, were further explored in the present investigation.

\section{Inhibition of YycG' enzyme activity by the derivatives}

To detect the enzyme inhibiting activities of the derivatives on the YycG protein, recombinant YycG' ( 29 kDa) was expressed as a fusion protein with an N-terminal maltose binding protein tag and purified using the ProBond ${ }^{\mathrm{TM}}$ Purification System (protein purity $>90 \%$ ). The enzymatic activity of the recombinant $\mathrm{YycG}^{\prime}$ was measured using the Kinase-Glo ${ }^{\mathrm{TM}}$ Luminescent Kinase assay, and all 6 derivatives displayed dose-dependent inhibition of its autophosphorylation activity. At $100 \mu \mathrm{mol} / \mathrm{L}$ (50 $\mathrm{\mu g} / \mathrm{mL}$ ), H2-10, H2-12, H2-20, H2-29, H2-27, and H2-28 inhibited $\mathrm{YycG}^{\prime}(0.13 \mu \mathrm{mol} / \mathrm{L})$ enzyme activity by $55.22 \%$, $63.70 \%, 83.65 \%, 50.75 \%, 78.31 \%$, and $58.59 \%$, respectively. The $\mathrm{IC}_{50}$ values of the six derivatives were $88.35 \mu \mathrm{mol} / \mathrm{L}(42.9$ $\mu \mathrm{g} / \mathrm{mL}), 61.15 \mu \mathrm{mol} / \mathrm{L}(31.9 \mu \mathrm{g} / \mathrm{mL}), 34.83 \mu \mathrm{mol} / \mathrm{L}(17.2 \mu \mathrm{g} /$ $\mathrm{mL}), 66.68 \mu \mathrm{mol} / \mathrm{L}(35.1 \mu \mathrm{g} / \mathrm{mL}), 22.15 \mu \mathrm{mol} / \mathrm{L}(10.9 \mu \mathrm{g} / \mathrm{mL})$, and $82.51 \mu \mathrm{mol} / \mathrm{L}(40.7 \mu \mathrm{g} / \mathrm{mL})$, respectively, and the $\mathrm{IC}_{50}$ of Compound 2 was $47.9 \mu \mathrm{mol} / \mathrm{L}(24.9 \mu \mathrm{g} / \mathrm{mL})$ (Table 1$)$.

\section{Antimicrobial activity of the derivatives}

The MIC values of the six derivatives for $S$ epidermidis ATCC 35984 and 12228 were determined. All 6 derivatives were found to inhibit bacterial growth more effectively than Compound 2. The MIC values of H2-10, H2-12, H2-20, H2-29, $\mathrm{H} 2-27$, and H2-28 on $S$ epidermidis ATCC 35984 were 24.3, 6.5, $6.2,3.3,3.1$, and $1.5 \mu \mathrm{g} / \mathrm{mL}$, respectively; and the MBC values were $48.6,52.2,12.4,52.6,12.4$, and $6.2 \mu \mathrm{g} / \mathrm{mL}$, respectively (Table 1). Additionally, all derivatives inhibited the growth of Sepidermidis ATCC 12228 and S aureus (ATCC 49230 and ATCC 25923) (Table 2), whereas they had no effect on the growth of $E$ coli strain ATCC 25922 at the highest tested concentration (100 $\mu \mathrm{g} / \mathrm{mL}$ ). The MIC/MBC values of these 6 derivatives ranged from $1 / 2$ to $1 / 4$, except for those of H2-12 and H2-29 (which had MIC/MBC values of $1 / 8$ and $1 / 16$, respectively).

Table 2. Anti-Staphylococcus activities of the derivatives.

\begin{tabular}{lcccc}
\hline & \multicolumn{4}{c}{ MIC $^{\mathrm{b}}(\mathrm{mg} / \mathrm{L})$} \\
Derivatives $^{\mathrm{a}}$ & $\begin{array}{c}\text { S epidermidis } \\
\text { ATCC 35984 }\end{array}$ & $\begin{array}{c}\text { S epidermidis } \\
\text { ATCC 12228 }\end{array}$ & $\begin{array}{c}\text { S aureus } \\
\text { ATCC 49230 }\end{array}$ & $\begin{array}{c}\text { S aureus } \\
\text { ATCC 25923 }\end{array}$ \\
\hline Compound 2 $^{\mathrm{c}}$ & 26.0 & 26.0 & 51.9 & 51.9 \\
$\mathrm{H} 2-10$ & 24.3 & 24.3 & 12.2 & 24.3 \\
$\mathrm{H} 2-12$ & 6.5 & 6.5 & 6.5 & 6.5 \\
$\mathrm{H} 2-20$ & 6.2 & 6.2 & 3.1 & 6.2 \\
$\mathrm{H} 2-29$ & 3.3 & 3.3 & 6.6 & 6.6 \\
$\mathrm{H} 2-27$ & 3.1 & 3.1 & 3.1 & 6.2 \\
$\mathrm{H} 2-28$ & 1.5 & 1.5 & 3.1 & 3.1 \\
\hline
\end{tabular}

${ }^{\text {a }}$ Stock solutions of the compounds were prepared in 0.1\% $(\mathrm{V} / \mathrm{V})$ DMSO.

${ }^{b} \mathrm{MIC}$ which represents minimal inhibitory concentration of the derivatives was determined by the broth microdilution (in tubes) method of the CLSI of America.

${ }^{\mathrm{C}} \mathrm{MIC}$ values for Compound $\mathbf{2}$ were determined in this work.

Effects of the derivatives on S epidermidis biofilm proliferation Effects of the derivatives on the proliferation of 6-h-old $S$ epidermidis ATCC 35984 biofilms were detected by a microtiter plate assay. All derivatives showed biofilm-killing effects on

Table 1. Biological effects of the six derivatives.

\begin{tabular}{|c|c|c|c|c|c|c|c|}
\hline Derivatives $^{a}$ & Molecule weight & $\mathrm{IC}_{50}^{\mathrm{b}}(\mathrm{mg} / \mathrm{L})$ & $\mathrm{MIC}^{\mathrm{c}}(\mathrm{mg} / \mathrm{L})$ & $\mathrm{MBC}^{\mathrm{c}}(\mathrm{mg} / \mathrm{L})$ & $\operatorname{MBKC}^{\mathrm{c}}(\mathrm{mg} / \mathrm{L})$ & $\mathrm{CC}_{50}{ }^{\mathrm{d}}(\mathrm{mg} / \mathrm{L})$ & Hemolysis $^{\mathrm{e}}(\%)$ \\
\hline Compound $\mathbf{2}^{f}$ & 519 & 24.9 & 26.0 & 51.9 & 51.9 & 50.0 & $2.31 \pm 0.35$ \\
\hline $\mathrm{H} 2-10$ & 486 & 42.9 & 24.3 & 48.6 & 24.3 & $>100.0$ & $0.36 \pm 0.11$ \\
\hline $\mathrm{H} 2-12$ & 522 & 31.9 & 6.5 & 52.2 & 13.1 & $>100.0$ & $0.16 \pm 0.03$ \\
\hline $\mathrm{H} 2-2 \mathrm{O}$ & 494 & 17.2 & 6.2 & 12.4 & 6.2 & $>100.0$ & $0.29 \pm 0.12$ \\
\hline $\mathrm{H} 2-29$ & 526 & 35.1 & 3.3 & 52.6 & 3.3 & $>100.0$ & $0.59 \pm 0.32$ \\
\hline $\mathrm{H} 2-27$ & 494 & 10.9 & 3.1 & 12.4 & 6.2 & $>100.0$ & $0.15 \pm 0.10$ \\
\hline $\mathrm{H} 2-28$ & 494 & 40.7 & 1.5 & 6.2 & 3.1 & $>100.0$ & $0.12 \pm 0.06$ \\
\hline
\end{tabular}

${ }^{\text {a }}$ Stock solutions of the compounds were prepared in $0.1 \%(v / v)$ DMSO.

${ }^{\mathrm{b}} \mathrm{IC}_{50}$ represents half maximal inhibitory concentration of the derivatives, which inhibit half of the autophosphorylation of recombinant YycG'.

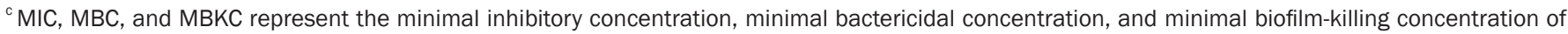
the derivatives against S epidermidis ATCC 35984.

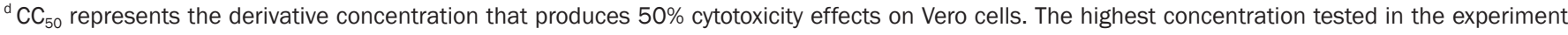
was $100 \mathrm{mg} / \mathrm{L}$.

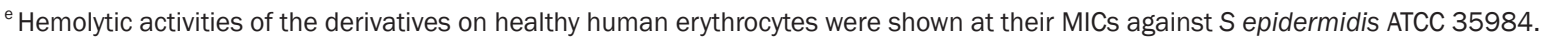

${ }^{\mathrm{f}}$ All values for Compound $\mathbf{2}$ were determined in this work. 
immature (6-h-old) S epidermidis ATCC 35984 biofilms (Figure 2), especially $\mathrm{H} 2-28$ and $\mathrm{H} 2-29$ [minimal biofilm-killing concentration $(\mathrm{MBKC})=3.1 \mathrm{\mu g} / \mathrm{mL}$ and $3.3 \mu \mathrm{g} / \mathrm{mL}$, respectively], which were stronger than Compound $2(\mathrm{MBKC}=51.9 \mu \mathrm{g} / \mathrm{mL})$ (Table 1).

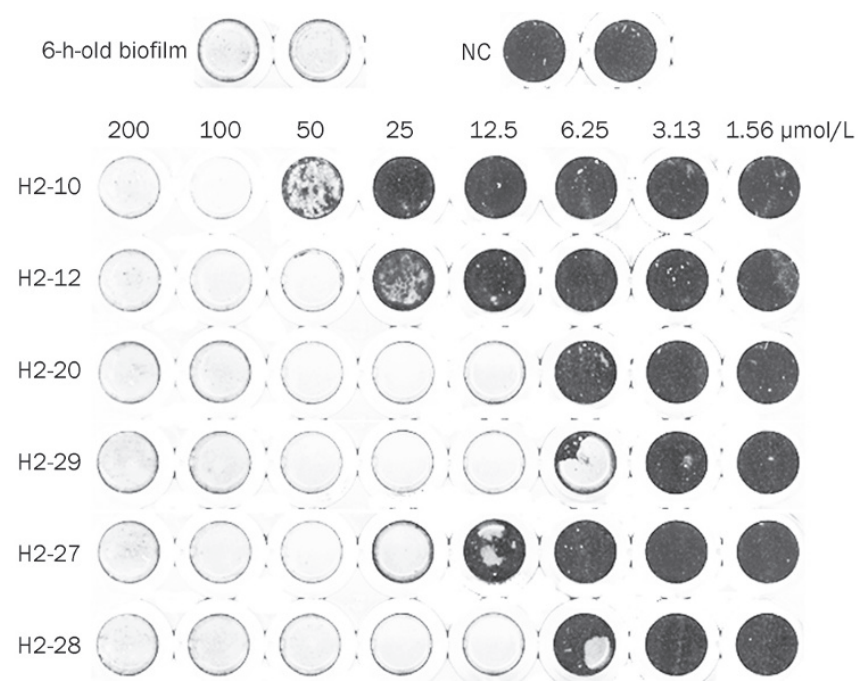

Figure 2. Macroscopic profiles of the biofilms co-cultured with the derivatives. S epidermidis strain ATCC 35984 was cultured in polystyrene microtiter plates at $37^{\circ} \mathrm{C}$ for $6 \mathrm{~h}$. After removal of planktonic cells, fresh medium containing serial dilutions of the derivatives was added to the 6-h-old biofilm, and then incubated at $37^{\circ} \mathrm{C}$ for another $18 \mathrm{~h}$. After incubation, the biofilms were visualized by crystal violet staining. The biofilm treated with $0.1 \%$ DMSO (NC) as well as the 6-h-old biofilm without further incubation served as controls. The images are representative of results from three independent experiments.

\section{Bactericidal effects of the derivatives on mature $S$ epidermidis biofilms}

The bactericidal activities of the derivatives on mature (24-h-old) $S$ epidermidis biofilms were detected by a confocal microscope; treatment with $0.1 \%$ DMSO or vancomycin (128 $\mu \mathrm{g} / \mathrm{mL}$ ) served as the controls. Each derivative was added individually to a mature biofilm at a concentration of $4 \times \mathrm{MIC}$, and incubated for $16 \mathrm{~h}$. Significant reductions of viable cells in the mature biofilms were observed by CLSM with LiveDead staining. All of the derivatives $(24.3 \mu \mathrm{g} / \mathrm{mL} \mathrm{H} 2-10,26.1$ $\mu \mathrm{g} / \mathrm{mL} \mathrm{H} 2-12,24.7 \mu \mathrm{g} / \mathrm{mL} \mathrm{H} 2-20,13.1 \mu \mathrm{g} / \mathrm{mL} \mathrm{H} 2-29,12.4$ $\mu \mathrm{g} / \mathrm{mL} \mathrm{H} 2-27$, and $12.4 \mu \mathrm{g} / \mathrm{mL} \mathrm{H2-28)} \mathrm{showed} \mathrm{bactericidal}$ activity against bacteria in mature biofilms, especially $\mathrm{H} 2-20$, H2-27, and H2-29 (Figures 3). In contrast, DMSO (0.1\%) and vancomycin (128 $\mu \mathrm{g} / \mathrm{mL}$, Bio Basic Inc, Canada) showed little effect on bacterial viability within a biofilm (Figure 3).

\section{Cytotoxicity and hemolysis of the derivatives in vitro}

The cytotoxicity of the derivatives to mammal cells was investigated using Vero cells and an MTT assay. Cells treated with $0.1 \%$ DMSO and untreated cells were used as controls. Compared with the control group, after treatment with the deriva- tives, no obvious cytotoxicity to Vero cells was detected. The $\mathrm{CC}_{50}$ values of all the derivatives were higher than $100 \mu \mathrm{g} / \mathrm{mL}$, which was the highest concentration used in the present study (Table 1).

Hemolysis of healthy human erythrocytes induced by the derivatives was examined, with vancomycin treatment as a control. Erythrocytes treated with 1\% Triton-X100 and untreated erythrocytes served as complete hemolysis (100\%) and no hemolysis $(0 \%)$ controls, respectively. At the MIC concentrations, none of the derivatives displayed obvious induction of hemolysis of healthy human erythrocytes $(<1 \%$ compared to the control), even at the highest concentrations (100 $\mu \mathrm{g} / \mathrm{mL}$ ). Derivatives H2-20, H2-27, and H2-28 had the lowest hemolytic activities (Table 1).

\section{Discussion}

$S$ epidermidis and $S$ aureus biofilm formation have become two of the most prevalent causes of nosocomial infections, especially in patients with prosthetic medical devices such as indwelling catheters and implanted foreign polymer bodies $^{[28,29]}$. As biofilms render bacteria increasingly resistant to multiple antibiotics ${ }^{[30-32]}$ and host defenses ${ }^{[33,34]}$, chronic biofilm infections persist in patients, and it often becomes necessary to remove the implanted devices ${ }^{[29]}$. New antimicrobial agents are thus urgently needed to combat biofilm-associated infections.

TCSs are composed of a sensor histidine kinase capable of autophosphorylation in response to an environmental signal and a response regulator that interacts with the phosphorylated HK and regulates the expression of specific genes ${ }^{[35]}$. The YycG/YycF TCS has been extensively studied in recent years because of its essential role in pathogenic bacteria ${ }^{[16,18,36]}$. YycG/YycF regulates bacterial murein biosynthesis ${ }^{[19,37-42]}$, cell division ${ }^{[16,17,39]}$, lipid integrity ${ }^{[18,37,42,43]}$, virulence factor expres$\operatorname{sion}^{[19,40,42,44-46]}$, exopolysaccharide biosynthesis, and biofilm formation ${ }^{[19,44,46-48]}$. The YycG/YycF TCS is highly conserved in low $\mathrm{G}+\mathrm{C}$ gram-positive bacteria but is absent in mammals and is thus considered a potential drug target in pathogenic bacteria $^{[24,27,49-52]}$. We previously reported two newly discovered compounds targeting $\mathrm{YycG}^{[24]}$ that clearly possess biofilm-killing activities against $S$ epidermidis ${ }^{[31]}$. To improve the antibacterial activities of these compounds, a series of derivatives were designed and synthesized by modifying the functional groups of Compound 2 while keeping the thiazolidione core structure intact ${ }^{[25]}$. When the (5-vinyl-furan-2-yl)benzoic acid fragment was incorporated into the thiazolidine4-ones scaffold, the rigidity of the determined compound was enhanced. That change might stabilize the thiazolidiones in the bonding pocket. Six out of thirty-five derivatives were found to possess higher antibacterial activities than the compound they were derived from, and they inhibited autophosphorylation of $\mathrm{YycG}$, suggesting that the bactericidal activity of these derivatives is based on inhibiting the enzyme activity of the YycG HK domain. However, the antibacterial activities of the derivatives did not always correlate with their $\mathrm{IC}_{50}$ values, as was the case with derivative $\mathrm{H} 2-28$ in the present 

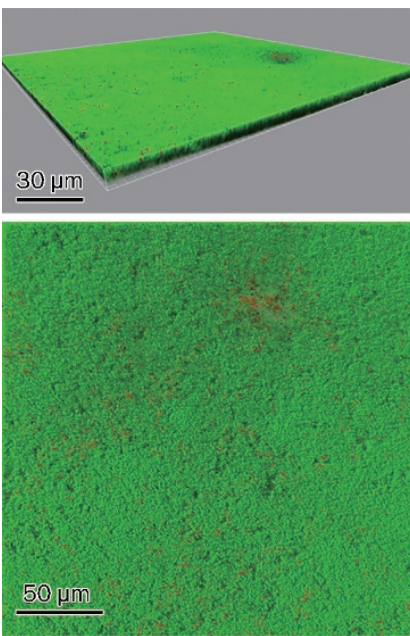

DMSO
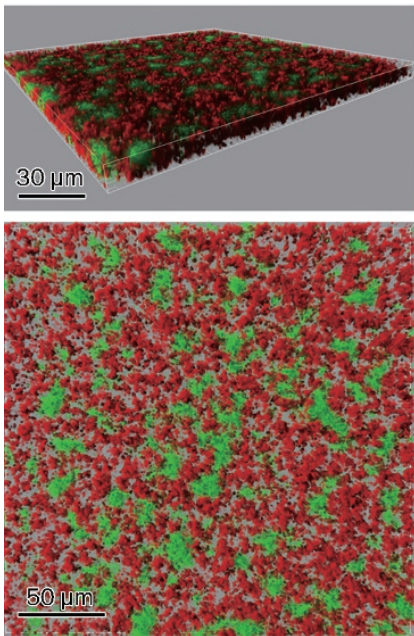

H2-20
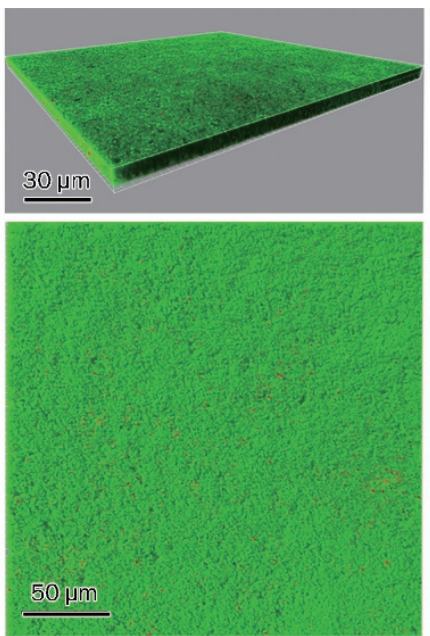

Vancomycin
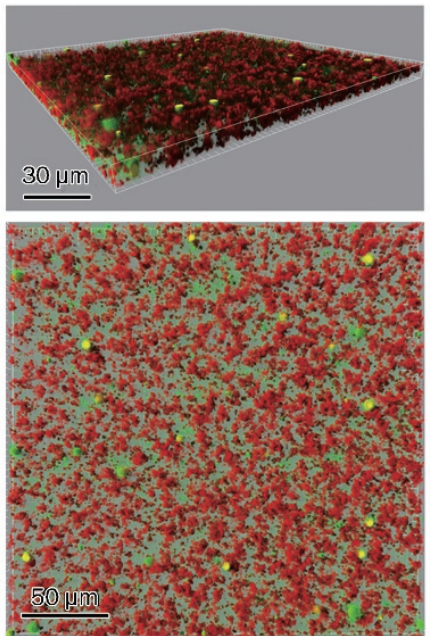

H2-29
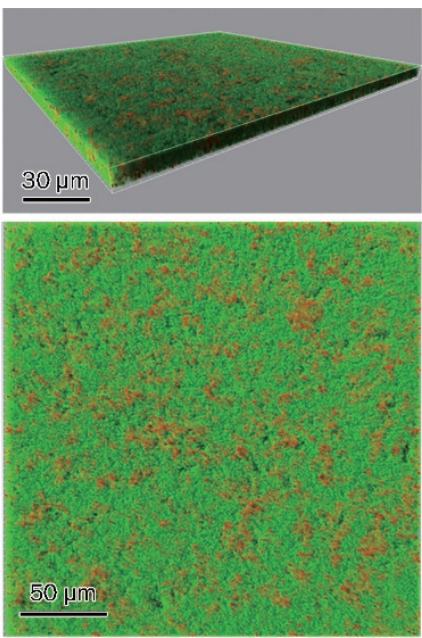

H2-10
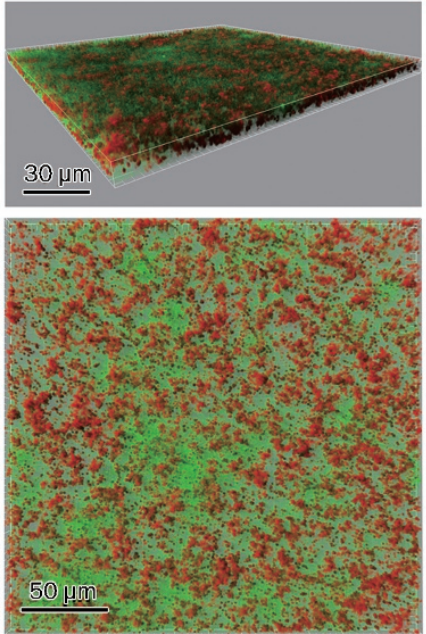

H2-27
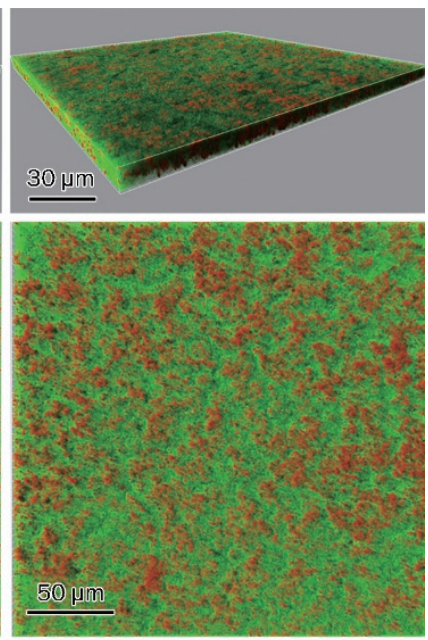

H2-12
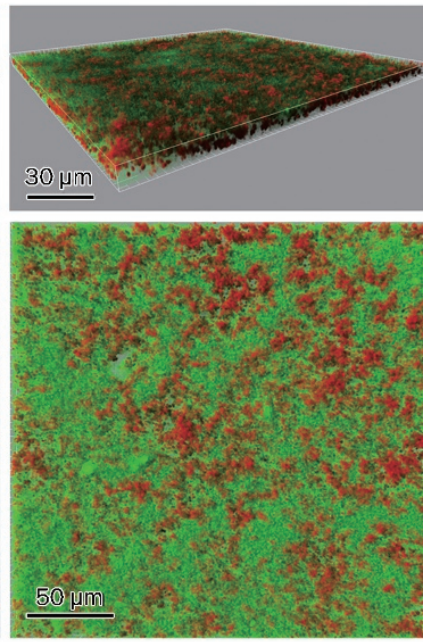

H2-28

Figure 3. Bactericidal effects of the derivatives on mature $S$ epidermidis biofilms. S epidermidis ATCC 35984 was grown in cover-glass cell-culture dishes at $37^{\circ} \mathrm{C}$ for $24 \mathrm{~h}$. Subsequent to the removal of planktonic cells, the 24 -h-old biofilms were further incubated at $37^{\circ} \mathrm{C}$ for another $16 \mathrm{~h}$ with fresh TSB containing the following substances: 0.1\% DMSO, $128 \mu \mathrm{g} / \mathrm{mL}$ vancomycin, $24.3 \mu \mathrm{g} / \mathrm{mL} \mathrm{H} 2-10,26.1 \mu \mathrm{g} / \mathrm{mL} \mathrm{H2}-12,24.7 \mu \mathrm{g} / \mathrm{mL} \mathrm{H2-20,13.1}$ $\mu \mathrm{g} / \mathrm{mL} \mathrm{H} 2-29,12.4 \mu \mathrm{g} / \mathrm{mL} \mathrm{H} 2-27$, or $12.4 \mu \mathrm{g} / \mathrm{mL} \mathrm{H} 2-28$. After incubation, the biofilms on the dishes were washed with normal saline and stained with Live-Dead reagents (containing SYTO9 and PI), and observed under CLSM using a 63×objective lens. Images representative of the results from three independent experiments were three-dimensionally reconstructed using Imaris software based on CLSM data at approximately $0.5 \mu \mathrm{m}$ increments. The green fluorescent cells are viable, while red fluorescent cells indicate dead bacteria.

study. This may be because the antibacterial activities of the derivatives may be affected by absorption by the bacterial cell, cell membrane permeability, or cellular metabolism, whereas the $\mathrm{IC}_{50}$ of the $\mathrm{YycG}$ inhibitors was determined by an autophosphorylation assay analyzing the direct interaction between the inhibitor and purified $\mathrm{YycG}^{\prime}$ protein in vitro. The YycG-targeting property of these derivatives accounts for their effectiveness against $S$ epidermidis and $S$ aureus, which are both low G+C gram-positive bacteria with highly conserved YycG/ YycF TCSs; this is also consistent with the low cytotoxicity of these derivatives to mammalian cells and with the absence of inhibitory activity on the growth of E coli strain ATCC 25922, as mammalian and $E$ coli cells do not have genes homologous to $y y c G / y y c F$.
Bacteria in biofilms are 100-1000 times more resistant to antibiotics than planktonic cells ${ }^{[30-32]}$, and vancomycin has little effect on $S$ epidermidis biofilms even at high concentrations ${ }^{[28,53]}$. The anti-biofilm activities of the six derivatives described here toward S epidermidis ATCC 35984 were improved compared to Compound 2. Lower concentrations of the derivatives compared with Compound $\mathbf{2}$ killed all bacteria in immature (6-h-old) biofilms and eliminated biofilm proliferation. More diluted derivatives did not eliminate biofilm formation but disrupted its structure so that it lost mechanical stability and could be washed away easily (Figure 2). The derivatives also displayed strong bactericidal activities toward cells in mature (24-h-old) biofilms, especially H2-20, H2-27, and H2-29, whereas Compound 2 mainly killed cells located at the bottom 
of the biofilm ${ }^{[28]}$.

In summary, six additional effective YycG inhibitors were designed and synthesized by modifying the chemical structure of the YycG inhibitor Compound 2. Their bactericidal and biofilm-killing activities were significantly better than those of Compound 2. The modification of anti-YycG leading compounds will help to discover new agents to combat biofilm infections and multidrug-resistant bacterial infections.

\section{Acknowledgements}

We would like to thank Prof Guo-qiang LIN, Shanghai Institute of Organic Chemistry, Chinese Academy of Sciences, for his invaluable advice. This work was supported by the Program of Ministry of Science and Technology of China (2012ZX09301002-005, 2012ZX10003008-010, and 2010DFA32100), the National Natural Science Foundation of China (30800036, 20942006, 21072095, and 81101214), the Scientific Technology Development Foundation of Shanghai (08JC1401600 and 10410700600), the High-Tech Research and Development Program of China (2006AA02A253), and the Specialized Research Fund for the Doctoral Program of Higher Education (SRFDP) (20100071120049).

\section{Author contribution}

Ren-zheng HUANG, Hua-yong LIU, Shi-qing HAN, and Di QU designed the research; Ren-zheng HUANG, Li-kang ZHENG, Hua-yong LIU, and Bin PAN performed most of the experiments; Tao ZHU, Dan-bin JIANG, and Wei WANG provided critical technical support; Jian HU and Yang WU analyzed the data; Ren-zheng HUANG, Hua-yong LIU, You-cong WU, Shi-qing HAN, and Di QU wrote the paper.

\section{References}

1 Rupp ME, Archer GL. Coagulase-negative staphylococci: pathogens associated with medical progress. Clin Infect Dis 1994; 19: 231-43; quiz 44-5.

2 Huebner J, Goldmann DA. Coagulase-negative staphylococci: role as pathogens. Annu Rev Med 1999; 50: 223-36.

3 Mermel LA, Farr BM, Sherertz RJ, Raad II, O'Grady N, Harris JS, et al. Guidelines for the management of intravascular catheter-related infections. Infect Control Hosp Epidemiol 2001; 22: 222-42.

4 Donlan RM, Costerton JW. Biofilms: survival mechanisms of clinically relevant microorganisms. Clin Microbiol Rev 2002; 15: 167-93.

5 Vandecasteele SJ, Peetermans WE, Merckx R, Van Eldere J. Expression of biofilm-associated genes in Staphylococcus epidermidis during in vitro and in vivo foreign body infections. J Infect Dis 2003; 188: 730-7.

6 Hoffman LR, D'Argenio DA, MacCoss MJ, Zhang Z, Jones RA, Miller SI. Aminoglycoside antibiotics induce bacterial biofilm formation. Nature 2005; 436: 1171-5.

7 Raad I, Alrahwan A, Rolston K. Staphylococcus epidermidis: emerging resistance and need for alternative agents. Clin Infect Dis 1998; 26 : 1182-7.

8 Zhang YQ, Ren SX, Li HL, Wang YX, Fu G, Yang J, et al. Genome-based analysis of virulence genes in a non-biofilm-forming Staphylococcus epidermidis strain (ATCC 12228). Mol Microbiol 2003; 49: 1577-93.

9 Gill SR, Fouts DE, Archer GL, Mongodin EF, Deboy RT, Ravel J, et al. Insights on evolution of virulence and resistance from the complete genome analysis of an early methicillin-resistant Staphylococcus aureus strain and a biofilm-producing methicillin-resistant Staphylococcus epidermidis strain. J Bacteriol 2005; 187: 2426-38.

10 Stock AM, Wylie DC, Mottonen JM, Lupas AN, Ninfa EG, Ninfa AJ, et al. Phosphoproteins involved in bacterial signal transduction. Cold Spring Harb Symp Quant Biol 1988; 53: 49-57.

11 Stock AM, Robinson VL, Goudreau PN. Two-component signal transduction. Annu Rev Biochem 2000; 69: 183-215.

12 West AH, Stock AM. Histidine kinases and response regulator proteins in two-component signaling systems. Trends Biochem Sci 2001; 26: 369-76.

13 Barrett JF, Hoch JA. Two-component signal transduction as a target for microbial anti-infective therapy. Antimicrob Agents Chemother 1998; 42: 1529-36.

14 Stephenson K, Hoch JA. Two-component and phosphorelay signaltransduction systems as therapeutic targets. Curr Opin Pharmacol 2002; 2: 507-12.

15 Stephenson K, Hoch JA. Virulence- and antibiotic resistanceassociated two-component signal transduction systems of Grampositive pathogenic bacteria as targets for antimicrobial therapy. Pharmacol Ther 2002; 93: 293-305.

16 Fabret C, Hoch JA. A two-component signal transduction system essential for growth of Bacillus subtilis: implications for anti-infective therapy. J Bacteriol 1998; 180: 6375-83.

17 Fukuchi K, Kasahara Y, Asai K, Kobayashi K, Moriya S, Ogasawara N. The essential two-component regulatory system encoded by yycF and yycG modulates expression of the ftsAZ operon in Bacillus subtilis. Microbiology 2000; 146: 1573-83.

18 Martin PK, Li T, Sun D, Biek DP, Schmid MB. Role in cell permeability of an essential two-component system in Staphylococcus aureus. J Bacteriol 1999; 181: 3666-73.

19 Dubrac S, Boneca IG, Poupel O, Msadek T. New insights into the WalK/WalR (YycG/YycF) essential signal transduction pathway reveal a major role in controlling cell wall metabolism and biofilm formation in Staphylococcus aureus. J Bacteriol 2007; 189: 8257-69.

20 Dubrac S, Msadek T. Tearing down the wall: peptidoglycan metabolism and the WalK/WaIR (YycG/YycF) essential two-component system. Adv Exp Med Biol 2008; 631: 214-28.

21 Okada A, Igarashi M, Okajima T, Kinoshita N, Umekita M, Sawa R, et al. Walkmycin B targets WalK (YycG), a histidine kinase essential for bacterial cell growth. J Antibiot (Tokyo) 2010; 63: 89-94.

22 Watanabe T, Hashimoto Y, Yamamoto K, Hirao K, Ishihama A, Hino $\mathrm{M}$, et al. Isolation and characterization of inhibitors of the essential histidine kinase, YycG in Bacillus subtilis and Staphylococcus aureus. J Antibiot (Tokyo) 2003; 56: 1045-52.

23 Yamamoto K, Kitayama T, Minagawa S, Watanabe T, Sawada S, Okamoto $\mathrm{T}$, et al. Antibacterial agents that inhibit histidine protein kinase YycG of Bacillus subtilis. Biosci Biotechnol Biochem 2001; 65: 2306-10.

24 Qin Z, Zhang J, Xu B, Chen L, Wu Y, Yang X, et al. Structure-based discovery of inhibitors of the YycG histidine kinase: new chemical leads to combat Staphylococcus epidermidis infections. BMC Microbiol 2006; 6: 96.

25 Qin Z, Lee B, Yang L, Zhang J, Yang X, Qu D, et al. Antimicrobial activities of YycG histidine kinase inhibitors against Staphylococcus epidermidis biofilms. FEMS Microbiol Lett 2007; 273: 149-56.

26 Pan B, Huang RZ, Han SQ, Qu D, Zhu ML, Wei P, et al. Design, synthesis, and antibiofilm activity of 2-arylimino-3-aryl-thiazolidine-4ones. Bioorg Med Chem Lett 2010; 20: 2461-4.

27 Clinical and Laboratory Standards Institute: Methods for dilution antimicrobial susceptibility tests for bacteria that grow aerobically, 7 th 
ed. In Approved standard M7-A7 Clinical and Laboratory Standards Institute, Villanova, PA, USA; 2006.

28 Christensen GD, Simpson WA, Younger JJ, Baddour LM, Barrett FF, Melton DM, et al. Adherence of coagulase-negative staphylococci to plastic tissue culture plates: a quantitative model for the adherence of staphylococci to medical devices. J Clin Microbiol 1985; 22: $996-$ 1006.

29 Mack D, Davies AP, Harris LG, Rohde H, Horstkotte MA, Knobloch JK. Microbial interactions in Staphylococcus epidermidis biofilms. Anal Bioanal Chem 2007; 387: 399-408.

30 Evans RC, Holmes CJ. Effect of vancomycin hydrochloride on Staphylococcus epidermidis biofilm associated with silicone elastomer. Antimicrob Agents Chemother 1987; 31: 889-94.

31 Baddour LM, Bettmann MA, Bolger AF, Epstein AE, Ferrieri P, Gerber MA, et al. Nonvalvular cardiovascular device-related infections. Clin Infect Dis 2004; 38: 1128-30.

32 Ceri H, Olson ME, Stremick C, Read RR, Morck D, Buret A. The Calgary Biofilm Device: new technology for rapid determination of antibiotic susceptibilities of bacterial biofilms. J Clin Microbiol 1999; 37: 1771-6.

33 Presterl E, Suchomel M, Eder M, Reichmann S, Lassnigg A, Graninger W, et al. Effects of alcohols, povidone-iodine and hydrogen peroxide on biofilms of Staphylococcus epidermidis. J Antimicrob Chemother 2007; 60: 417-20.

34 Mulcahy $\mathrm{H}$, Charron-Mazenod L, Lewenza S. Extracellular DNA chelates cations and induces antibiotic resistance in Pseudomonas aeruginosa biofilms. PLoS Pathog 2008; 4: e1000213.

35 Gao R, Stock AM. Biological insights from structures of twocomponent proteins. Annu Rev Microbiol 2009; 63: 133-54.

36 Wagner C, Saizieu Ad A, Schonfeld HJ, Kamber M, Lange R, Thompson $\mathrm{CJ}$, et al. Genetic analysis and functional characterization of the Streptococcus pneumoniae vic operon. Infect Immun 2002; 70 : 6121-8.

37 Bisicchia P, Noone D, Lioliou E, Howell A, Quigley S, Jensen T, et al. The essential YycFG two-component system controls cell wall metabolism in Bacillus subtilis. Mol Microbiol 2007; 65: 180-200.

38 Dubrac S, Msadek T. Identification of genes controlled by the essential YycG/YycF two-component system of Staphylococcus aureus. J Bacteriol 2004; 186: 1175-81.

39 Howell A, Dubrac S, Andersen KK, Noone D, Fert J, Msadek T, et al. Genes controlled by the essential YycG/YycF two-component system of Bacillus subtilis revealed through a novel hybrid regulator approach. Mol Microbiol 2003; 49: 1639-55.

40 Liu M, Hanks TS, Zhang J, McClure MJ, Siemsen DW, Elser JL, et al. Defects in ex vivo and in vivo growth and sensitivity to osmotic stress of group A Streptococcus caused by interruption of response regulator gene vicR. Microbiology 2006; 152: 967-78.
41 Ng WL, Robertson GT, Kazmierczak KM, Zhao J, Gilmour R, Winkler ME. Constitutive expression of PcsB suppresses the requirement for the essential VicR (YycF) response regulator in Streptococcus pneumoniae R6. Mol Microbiol 2003; 50: 1647-63.

$42 \mathrm{Ng}$ WL, Tsui HC, Winkler ME. Regulation of the pspA virulence factor and essential pcsB murein biosynthetic genes by the phosphorylated VicR (YycF) response regulator in Streptococcus pneumoniae. J Bacteriol 2005; 187: 7444-59.

43 Mohedano ML, Overweg K, de la Fuente A, Reuter M, Altabe S, Mulholland $F$, et al. Evidence that the essential response regulator YycF in Streptococcus pneumoniae modulates expression of fatty acid biosynthesis genes and alters membrane composition. J Bacteriol 2005; 187: 2357-67.

44 Ahn SJ, Wen ZT, Burne RA. Effects of oxygen on virulence traits of Streptococcus mutans. J Bacteriol 2007; 189: 8519-27.

45 Kadioglu A, Echenique J, Manco S, Trombe MC, Andrew PW. The MicAB two-component signaling system is involved in virulence of Streptococcus pneumoniae. Infect Immun 2003; 71: 6676-9.

46 Senadheera MD, Guggenheim B, Spatafora GA, Huang YC, Choi J, Hung DC, et al. A VicRK signal transduction system in Streptococcus mutans affects gtfBCD, gbpB, and ftf expression, biofilm formation, and genetic competence development. J Bacteriol 2005; 187: 406476.

47 Ahn SJ, Burne RA. Effects of oxygen on biofilm formation and the AtIA autolysin of Streptococcus mutans. J Bacteriol 2007; 189: 6293302.

48 Shemesh M, Tam A, Feldman M, Steinberg D. Differential expression profiles of Streptococcus mutans ftf, gtf and vicR genes in the presence of dietary carbohydrates at early and late exponential growth phases. Carbohydr Res 2006; 341: 2090-7.

49 Gilmour R, Foster JE, Sheng Q, McClain JR, Riley A, Sun PM, et al. New class of competitive inhibitor of bacterial histidine kinases. J Bacteriol 2005; 187: 8196-200.

50 Kitayama T, Iwabuchi R, Minagawa S, Sawada S, Okumura R, Hoshino $\mathrm{K}$, et al. Synthesis of a novel inhibitor against MRSA and VRE: preparation from zerumbone ring opening material showing histidinekinase inhibition. Bioorg Med Chem Lett 2007; 17: 1098-101.

51 Okada A, Gotoh Y, Watanabe T, Furuta E, Yamamoto K, Utsumi R. Targeting two-component signal transduction: a novel drug discovery system. Methods Enzymol 2007; 422: 386-95.

52 Stephenson K, Hoch JA. Developing inhibitors to selectively target two-component and phosphorelay signal transduction systems of pathogenic microorganisms. Curr Med Chem 2004; 11: 765-73.

53 Khardori N, Yassien M, Wilson K. Tolerance of Staphylococcus epidermidis grown from indwelling vascular catheters to antimicrobial agents. J Ind Microbiol 1995; 15: 148-51. 